\title{
Effect of Anterior Capsule Polishing on the Need for Laser Capsulotomy
}

\author{
Hamad Elzarrug1,2*, Kevin M. Miller², Yu Fei², Shahriar Farzad², Yaroslav 0. Grusha² \\ ${ }^{1}$ Department of Ophthalmology, Faculty of Medicine, Benghazi University, Benghazi, Libya \\ ${ }^{2}$ Department of Ophthalmology, Jules Stein Eye Institute, David Geffen School of Medicine at UCLA, Los Angeles, CA, USA \\ Email: *olaharb2015@gmail.com
}

How to cite this paper: Elzarrug, H., Miller, K.M., Fei, Y., Farzad, S. and Grusha, Y.O. (2017) Effect of Anterior Capsule Polishing on the Need for Laser Capsulotomy. Open Journal of Ophthalmology, 7, 319-331.

https://doi.org/10.4236/ojoph.2017.74041

Received: October 18, 2017

Accepted: November 14, 2017

Published: November 17, 2017

Copyright $\odot 2017$ by authors and Scientific Research Publishing Inc. This work is licensed under the Creative Commons Attribution International License (CC BY 4.0).

http://creativecommons.org/licenses/by/4.0/

\begin{abstract}
Purpose: To determine the effect of anterior capsule polishing (APC) on the rate of posterior capsule opacification (PCO) as assessed by the need for laser posterior capsulotomy. Setting: University-based clinical practice, Jules Stein Eye Institute, Los Angles, California, USA. Methods: This study involved a retrospective review of eyes that underwent phacoemulsification and intraocular lens implantation between September 1991 and June 1999. Lens epithelial cells in the 763 study eyes were mechanically debrided or polished from the inside surface of the anterior capsules using a pair of Shepherd-Rentsch (Morning STAAR Inc.) capsule polishers. The 484 control eyes that had surgery earlier in the series were not polished. The rate of laser capsulotomy in the ACP and the non-ACP groups was compared using a Kaplan-Meier survival analysis. Multivariate regression was performed to determine if variables other than ACP influenced the need for laser posterior capsulotomy. Results: We identified 763 eyes that had ACP and 484 that did not. At the 24-month follow-up interval, $26.6 \%$ of the eyes in the ACP group had received a capsulotomy versus $19.50 \%$ in the non-APC. Next, a separate study was done using only one eye per patient, taking the patient as the unit of analysis. Again the capsulotomy rate was higher in the ACP group compared to the non-ACP (1.02 per 100 person-months of follow-up vs. 0.74 per 100 person-months of follow-up). Finally, a third Kaplan-Meier analysis was done on 52 patients that had one eye treated with the ACP procedure and the other eye with the non-ACP procedure. Although the log-rank test showed the statistical significant of this analysis to be borderline, the results again favored the non-ACP group with a lower capsulotomy rate. Multivariate analysis showed very similar results to the above univariate studies. The mean time to capsulotomy was 46 months for the polished group and 70 months for the unpolished group. The severity of cataract $(\mathrm{p}=0.46)$ and the type of haptics $(\mathrm{p}=0.86)$ did not influence the rate of capsulotomy. Plate haptic IOLS had a higher rate of cap-
\end{abstract}


sulotomy than loop haptic IOLS $(\mathrm{p}=0.001)$. Conclusions: Polishing of the anterior capsule with Shepherd-Rentsch polishers may unexpectedly increase the rate of posterior capsule opacification in eyes with round-edge silicone lenses.

\section{Keywords}

Anterior Capsule Polishing, Posterior Capsule Opacification, Laser, Posterior Capsulotomy

\section{Introduction}

Posterior Capsule Opacification (PCO) is the most common late complication following phacoemulsification and intraocular lens (IOL) implantation. The main cause of PCO is remnant lens epithelial cells (LEC) proliferating and migrating across the posterior lens capsule.

To prevent postoperative posterior capsule opacification (PCO) caused by residual lens epithelial cell proliferation, many surgical techniques to facilitate LEC removal during cataract surgery have been developed [1]-[7]. Several studies report that LEC removal was associated with reduction or delay in posterior capsule fibrosis and capsular bag contraction [3] [5] [8] and [9]. A study by Nishi and Nishi found that mechanical intraoperative anterior capsule polishing (ACP) reduces the rate by $7.1 \%$ [10]. However, other studies challenge those findings and conclude that changes in surgical technique, such as capsule polishing, fail to prevent PCO [11] [12] [13] [14] [15], although a capsulorhexis size that lies on the optic diameter appears to be beneficial [16]. Moreover, capsular polishing is reported to exacerbate PCO, as found in the long-term follow-up studies [11] [12] [13]. In recent years, with the development and rising popularity of new generation of premium (IOLs) like the multifocal, toric, accommodative, the clinical significance of the LEC removal may become more important when a maximum optical zone is required (e.g., multifocal IOLS) [5].

Cataract surgeons have renewed concern about capsule opacity and capsule contraction due to remnant cell proliferation, which can undermine the effectiveness of IOLs by creating glare, halos and difficulties with night vision [17]. Refractive cataract surgery requires an extremely high level of surgical accuracy.

The purpose of the present study was to determine whether anterior capsule polishing to remove LECs after lens substance extraction reduces LEC proliferation rate of $\mathrm{PCO}$ as compared to eyes that were not polished.

In order to be able to solely assess the effect of capsule polishing upon PCO, we have also examined the possible contributions of age, sex, type of anesthesia, incision location (corneal or scleral), cataract severity, and IOL type (loop haptic or plate).

\section{Materials and Methods}

We reviewed the medical records of 938 different patients who underwent pha- 
coemulsification and silicone intraocular lens implantation between September 1991 and June 1999. All patients underwent cataract surgery by Kevin M. Miller, M.D., at the Jules Stein Eye Institute in Los Angeles, California. Eyes that had other procedures done at the time of cataract surgery (e.g. peripheral corneal relaxing incisions, trabeculotomies, stretch synechiolysis, etc.) as well as those cases in which the posterior capsule was torn intraoperative, and those in which posterior capsule plaque was identified were excluded from the study.

In our record review we recorded demographic information, type of anesthesia, the nuclear density of cataract, whether or not the anterior capsule was polished during surgery, the type of silicone IOL implanted, whether or not a capsulotomy was performed, and the interval between cataract surgery and either the date of the capsulotomy or the date of the last office visit.

In total, there were 1247 eyes studied, 763 of which had intraoperative anterior capsule polishing and 484, which did not have any anterior capsule polishing.

Prior to surgery, all cataracts were graded at the slit lamp on a 0 to 4 scale according to the degree of the nuclear sclerosis. In this grading scheme, 0 represented no cataract, 1 trace cataract, 2 - 3 moderate degrees of cataract, and 4-advanced cataract. Dense brown cataracts were assigned a score of 4 , while white cataracts in which the nucleus could not be seen were assigned a score of 2.5. There were less than 20 cases with white cataract. Assessment of the degree of nuclear sclerosis was done with the slit lamp beam positioned 45 degrees from the pupillary axis.

Early in the study phacoemulsification was performed through either a $4 \mathrm{~mm}$ sclerocorneal tunnel incision. Later in the study eyes had surgery through 2.6 $3.5 \mathrm{~mm}$ clear corneal incision. After injection of viscoelastic into the anterior chamber a round capsulorhexis, approximately $5.5 \mathrm{~mm}$ in diameter, was fashioned with Utrata forceps. Balanced saline solution was injected beneath the anterior capsule to hydrodissect the lens nucleus from the capsule. A phacoemulsification probe was used to take out the nucleus by a divide and conquer technique and the cortex was thoroughly removed using an irrigation-aspiration probe. The same probe was used to clean the posterior capsule of any debris. In a few cases, if a fibrous posterior capsule plaque was identified, the eye was excluded from the analysis because it automatically qualified for a subsequent capsulotomy. Viscoelastic was injected to form the capsular bag and the anterior chamber.

Study group assignment was determined by whether or not the anterior capsule was polished, and this dictated by when each eye had surgery. Eyes in the control group had surgery between 1991 and 1996. During these years the surgeon had not yet begun performing ACP. Eyes in the study group underwent surgery between 1996 and 1999. The anterior capsules of the study group were polished using a pair of Shepherd-Rentsch (Morning STAAR Inc.) capsule polisher. One polisher is used to debride LECs to the right of the incision and the other to debride LECS to the left of the incision. The procedure is done using 
visual rather than tactile feedback under slightly higher magnification than the rest of the operation. Once LECs are scraped away from the anterior capsule they can be seen floating in the viscoelastic. Whenever a pupil was small, the $\mathrm{ACP}$ was done beneath the iris without the benefit of direct visualization.

Implanting foldable, round-edge silicone IOL, removing the viscoelastic and LECS, and closing the incisions by stromal hydration completed surgery. Square edges IOLs were not yet available.

The follow-up was defined as the interval between cataract surgery and either the date of an Nd: YAG laser posterior capsulotomy or the date of most recent office visit. At each office visit, patient were examined to determine if a capsulotomy had been performed elsewhere. If a capsulotomy was observed, the date of the procedure was ascertained. No patients were called in for examinations in this study.

A Nd: YAG posterior capsulotomy was performed by this office whenever a patients snellen best corrected visual acuity (BCVA) was reduced as a result of PCO under standard lighting or glare conditions, or when PCO limited the view of the ocular fundus. In the cases of 20/20 or better BCVA, subjective complaints such as glare, starbursts, halos, ghost images, multiplopia, or loss of contrast were considered.

Three set of Kaplan-Meier analysis were performed using time to capsulotomy as independent variable and whether or not ACP was performed as the independent variable. In the first analysis all eyes were combined, including two eyes of the same patient if both eyes had surgery during the study interval. In the second analysis only one eye per patient was included in the analysis. The first eye to have cataract surgery was chosen. In the third analysis the left and right eyes of a small subset of patients who had bilateral cataract surgery were compared. One eye of each patient had ACP while the other eye did not.

The long -rank test was performed to establish the statistical significance of the data, and to determine the influence of the gender, type of the anesthesia (injection vs. topical), cataract density, and IOL type (loop haptic vs. plate haptic) on the need for capsulotomy.

\section{Results}

1247 eyes from 938 patients met the inclusion criteria of these $55 \%$ of eyes were female and $45 \%$ were male, the median age at the time of cataract surgery was 74 years (19 to 94) and the mean age was $71.0 \pm 12$ (SD) years. Median follow up was 30.7 months ( 0 to 220.4 ) and the mean follow up was $44.0 \pm 43.5$ months.

There were 763 eyes in the study group, all had ACP during cataract surgery, and there were 484 eyes in the control group none of which had ACP done during cataract surgery. The overall patient demographics and surgical information showed that in general, the two procedure groups are similar in gender, eye, type of anesthesia, cataract severity and the age (Table 1 and Table 2).

However the ACP study group had median follow up range 28.1 months (0.0 
to 164.7), while the non- ACP control group had a median follow up interval of 35.4 months ( 0.3 to 220.4$) \mathrm{p}=0.009$.

Overall, there were 499 eyes had capsulotomy. The median time from phacoemulsification until capsulotomy was 48.5 months based on a Kaplan-Meier Table 1. Descriptive statistics for all 1247 eyes (938 patients).

\begin{tabular}{|c|c|}
\hline Characteristics & $\mathrm{N}(\%)$ \\
\hline \multicolumn{2}{|l|}{ Sex } \\
\hline Female & $687(55.1 \%)$ \\
\hline Male & $560(44.9 \%)$ \\
\hline \multicolumn{2}{|l|}{ Eye } \\
\hline Left & $617(49.5 \%)$ \\
\hline Right & $630(50.5 \%)$ \\
\hline \multicolumn{2}{|l|}{ Procedure } \\
\hline IOL without ACP & $484(38.8 \%)$ \\
\hline IOL with ACP & $763(61.2 \%)$ \\
\hline \multicolumn{2}{|l|}{ Anesthesia } \\
\hline General & $14(1.1 \%)$ \\
\hline Injection & $723(58.0 \%)$ \\
\hline Topical & $509(40.8 \%)$ \\
\hline \multicolumn{2}{|l|}{ Cataract severity score } \\
\hline 0 & $136(10.9 \%)$ \\
\hline $1,1.5$ & $265(21.3 \%)$ \\
\hline $2,2.5$ & $429(34.4 \%)$ \\
\hline $3,3.5,4$ & $417(33.4 \%)$ \\
\hline \multicolumn{2}{|l|}{ Intraocular lens type } \\
\hline Loop haptic & $325(26.1 \%)$ \\
\hline Plate haptic & $922(73.9 \%)$ \\
\hline \multicolumn{2}{|l|}{ Intraocular lens } \\
\hline AA & $913(73.2 \%)$ \\
\hline MA & $149(11.9 \%)$ \\
\hline SI & $97(7.8 \%)$ \\
\hline Other & $88(7.1 \%)$ \\
\hline \multicolumn{2}{|l|}{ Age (years) } \\
\hline Mean \pm SD & $71.0 \pm 12.1$ \\
\hline Median (range) & $74(19$ to 94$)$ \\
\hline \multicolumn{2}{|c|}{ Duration of follow-up (months) } \\
\hline Mean \pm SD & $44.0 \pm 43.5$ \\
\hline Median (range) & 30.7 (0 to 220.4 ) \\
\hline
\end{tabular}


Table 2. Descriptive statistics for all 1247 eyes (938 patients) by whether anterior capsule polishing (ACP) was performed.

\begin{tabular}{|c|c|c|c|}
\hline Characteristics & $\begin{array}{c}\text { IOL without ACP } \\
\mathrm{n}=484\end{array}$ & $\begin{array}{c}\text { IOL with ACP } \\
n=763\end{array}$ & P-value* \\
\hline Sex & & & 0.86 \\
\hline Female & $265(54.8 \%)$ & $422(55.3 \%)$ & \\
\hline Male & $219(45.2 \%)$ & $341(44.7 \%)$ & \\
\hline Eye & & & 0.30 \\
\hline Left & $230(47.5 \%)$ & $387(50.7 \%)$ & \\
\hline Right & $254(52.5 \%)$ & $376(49.3 \%)$ & \\
\hline Anesthesia & & & 0.044 \\
\hline General & $1(0.2 \%)$ & $13(1.7 \%)$ & \\
\hline Injection & $287(59.3 \%)$ & $436(57.1 \%)$ & \\
\hline Topical & $196(40.5 \%)$ & $313(41.0 \%)$ & \\
\hline Cataract severity score & & & 0.020 \\
\hline 0 & $66(13.6 \%)$ & $70(9.2 \%)$ & \\
\hline $1,1.5$ & $111(22.9 \%)$ & $154(20.2 \%)$ & \\
\hline $2,2.5$ & $148(30.6 \%)$ & $281(36.8 \%)$ & \\
\hline $3,3.5,4$ & $159(32.9 \%)$ & $258(33.8 \%)$ & \\
\hline Intraocular lens type & & & $<0.0001$ \\
\hline Loop haptic & $177(36.6 \%)$ & $148(19.4 \%)$ & \\
\hline Plate haptic & $307(63.4 \%)$ & $615(80.6 \%)$ & \\
\hline Intraocular lens & & & $<0.0001$ \\
\hline AA & $299(61.8 \%)$ & $614(80.5 \%)$ & \\
\hline MA & $59(12.2 \%)$ & $90(11.8 \%)$ & \\
\hline SI & $93(19.2 \%)$ & $4(0.5 \%)$ & \\
\hline Other & $33(6.8 \%)$ & $55(7.2 \%)$ & \\
\hline Age (years) & & & 0.062 \\
\hline Mean \pm SD & $70.4 \pm 12.4$ & $71.3 \pm 12.0$ & \\
\hline Median (range) & 72.5 (19 to 94$)$ & 74 (21 to 93$)$ & \\
\hline Duration of follow-up (months) & & & 0.009 \\
\hline Mean \pm SD & $48.5 \pm 46.7$ & $41.2 \pm 41.1$ & \\
\hline Median (range) & $35.4(0.3$ to 220.4$)$ & $28.1(0.0$ to 164.7$)$ & \\
\hline
\end{tabular}

survival analysis.

Next, a univariate analysis was done o generate and compare the Kaplan-Meier curves for time until capsulotomy in the ACP treated group and the non-ACP group (Figure 1(a) \& Figure 1(b)), the curves showed that over the time, the ACP treatment group does worse than the non-ACP group.

Among 484 unpolished eyes, 173 (35.7\%) cases had capsulotomy, resulted in a 


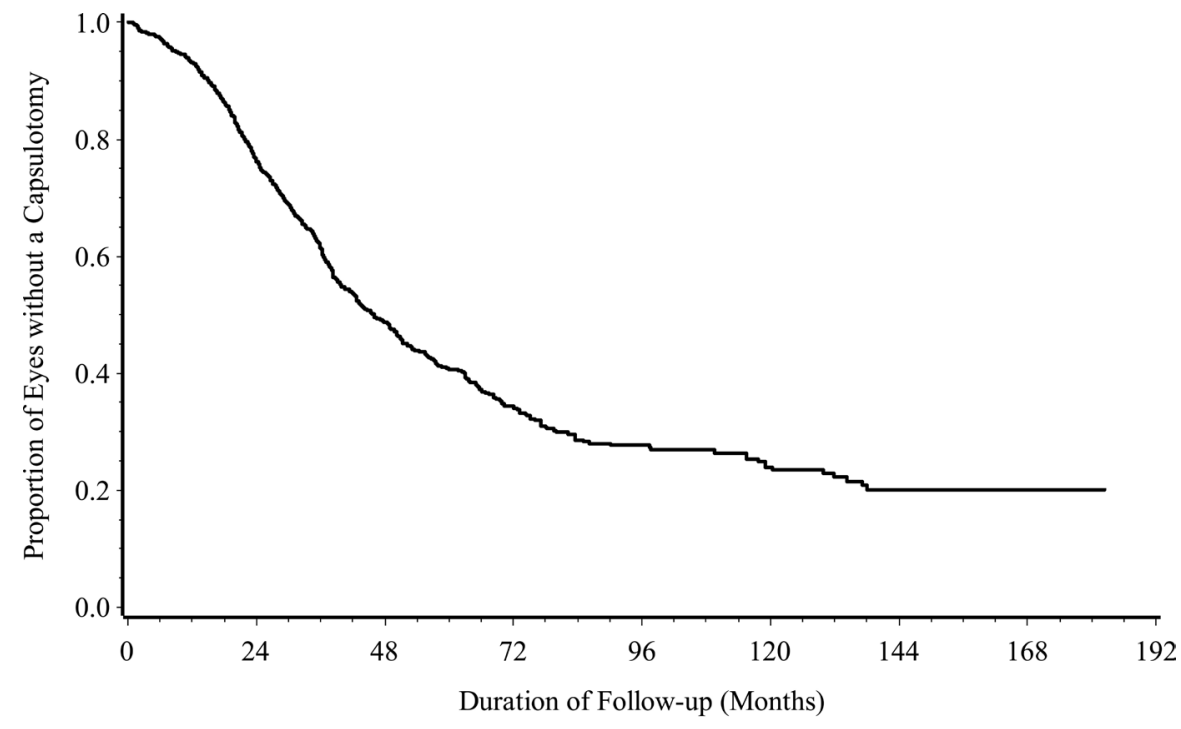

(a)

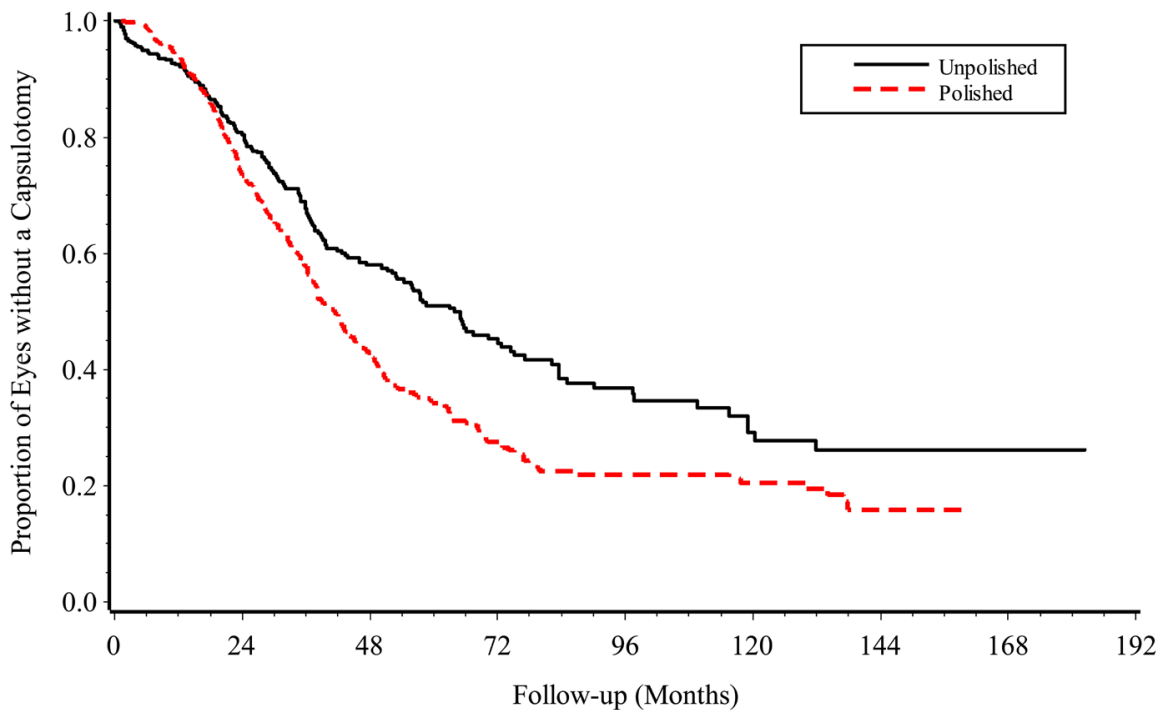

(b)

Figure 1. (a) Kaplan Meier survival curve of capsulotomy after cataract surgery. All 1247 eyes were included and viewed as independent in the analysis although there were 938 patients. (b) Kaplan Meier survival curves of capsulotomy after cataract surgery by type of procedure (polished vs. unpolished). All 1247 eyes were included and viewed as independent in the analysis although there were 938 patients.

crude rate of 0.74 per person per 100 person-months. Among 763 polished eyes, 326 eyes had capsulotomy, resulted in a crude rate of 1.04 per 100 person-months. The polished group had statistical significant higher rate of capsulotomy (long rank test $\mathrm{p}=0.0002$ ). At 24 months of follow up, $26.6 \%$ had capsulotomy in the polished group and 19.5 had capsulotomy in the unpolished group.

Univariate analysis was also done to look for other possible factors that may affect the time to capsulotomy. The long rank test showed that there is no statistically significant in time until capsulotomy between eyes with loop and plate 
type $\mathrm{p}=0.86$. Next, we looked at cataract severity as a possible predictor of time until capsulotomy. The cases were categorized into two group, severity $\leq 2$ and $\geq 2$. Again, the long rank test showed that there is no statistically significant in time to capsulotomy between the two group $\mathrm{p}=0.46$. Next looked at type of anesthesia as a possible factor that may affect the time to capsulotomy. The long rank test showed there is no statistically significant $\mathrm{p}=0.36$.

We then performed a multivariate cox proportional hazard regression model including procedure (ACP vs. non-ACP), gender (male vs. female), IOL type (loop vs. plate) and anesthesia (injection vs. topical), excluding eyes with general anesthesia, procedure was statistically significant with hazard ratio of 1.41 (95\% confidence interval $(\mathrm{CI})=1.17-1.70 ; \mathrm{p}=0.0004$. Gender had borderline significant $(\mathrm{p}=0.048)$, and IOL type $(\mathrm{p}=0.91)$ and anesthesia $(\mathrm{p}=0.44)$ were not related to time until capsulotomy.

Next, instead of treating all 1247 eyes as independent units of observation, we looked at the data by taking each patient as the unit of analysis. If the patient had phacoemulsification and IOL implantation performed on both eyes, only the first eye was selected. This gives us a total of 938 eyes to study. We did a univariate analysis, comparing the Kaplan-Meier curves in the ACP group and the non-ACP group (Figure 2(a) \& Figure 2(b)).

The results were very similar to those found using all 1247 eyes. The crude capsulotomy rate for the non-ACP treated patients was 0.74 per 100 person per months of follow up, and in the ACP treated patients, the rate was 1.02 person month of the follow up. The polished group had statistically significant higher rate of capsulotomy (long-rank test $\mathrm{p}=0.0006$ ). At 24 months of follow up, $25.3 \%$ had capsulotomy in the polished group and 19.1 had capsulotomy in the non-ACP group.

Similar result from a multivariate cox proportional hazard regression model including procedure (ACP vs. non-ACP), gender (male vs. female), IOL type (loop vs. plate) and anesthesia (injection vs. topical) excluding eye with general, were found as those found when all 1247 eyes were used, again the procedure was statistically significant with hazard ratio of $1.43(95 \% \mathrm{CI}=1.16-1.77, \mathrm{p}=$ $0.001)$. Gender $(p=0.095)$, IOL type $(p=0.82)$ and anesthesia $(p=0.82)$ were not related to time until capsulotomy.

Finally, we identified 52 patients who had bilateral sequential surgery with $\mathrm{ACP}$ in one eye and without ACP in the other eye. In each of the procedure groups 16 capsulotomy were performed.

Kaplan-Meier curves were generated to compare the two groups (Figure 3). The crude capsulotomy rate was 0.89 per 100 person-months of follow up in the ACP group and 0.49 per 100 person-months of follow $p$ in the non-ACP group. Again the polished group had slightly higher rate of capsulotomy (long-rank test $\mathrm{p}=0.063$ ) and the shorter follow-up (Wilcoxon signed rank test $\mathrm{p}<0.0001$ ).

\section{Discussion}

Our study consisted of a total of 1247 eyes from 938 different patients that 


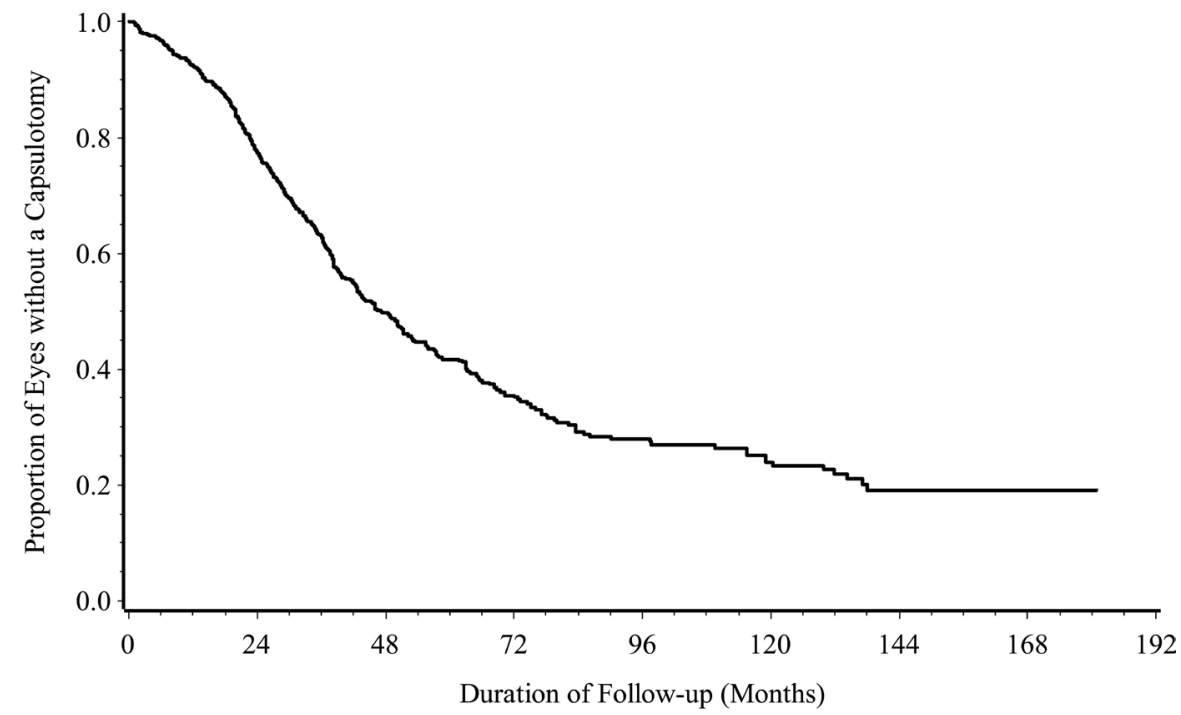

(a)

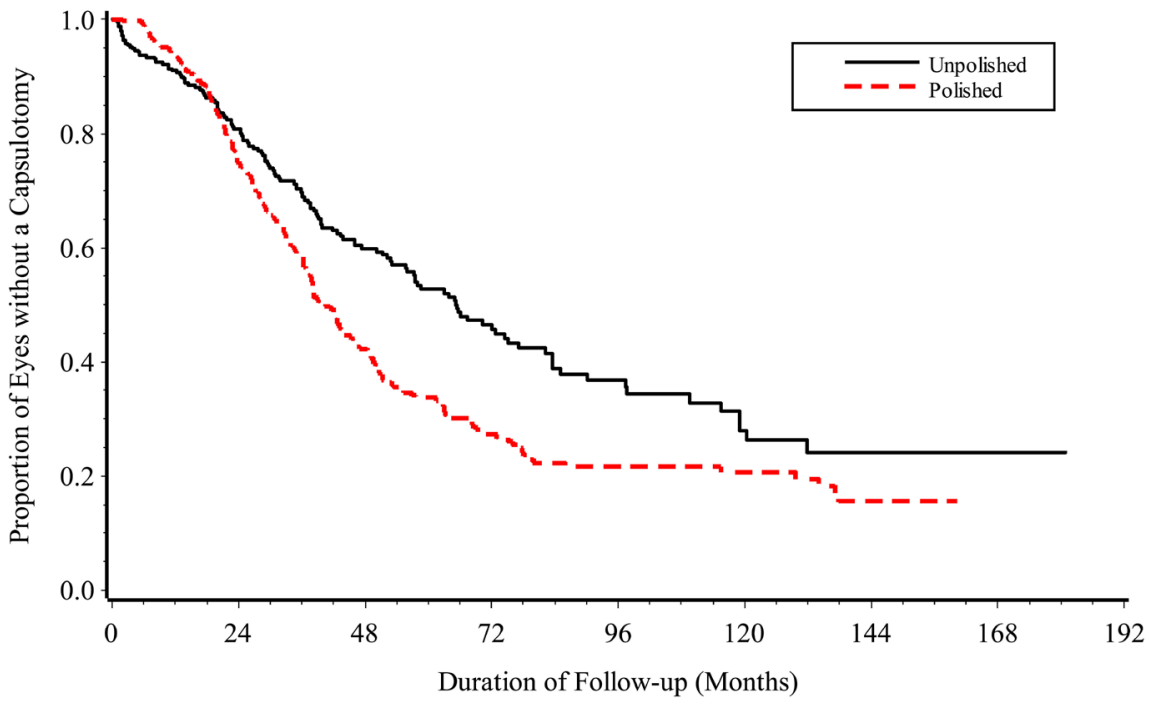

(b)

Figure 2. (a) Kaplan Meier survival curve of capsulotomy after cataract surgery. One eye per patient (938 eyes) was included in the analysis. (b) Kaplan Meier survival curve of capsulotomy after cataract surgery by type of procedure (polished vs. unpolished). One eye per patient (938 eyes) was included in the analysis.

underwent phacoemulsification and silicone lens implantation. It was found that the crude capsulotomy rate in the 763 eyes that received the ACP treatment was actually higher than in the 484 eyes, which did not have any ACP during cataract surgery (1.04 per 100 person-months of follow-up vs. 0.74 per 100 person-months of follow-up). The polished group had statistically significant higher rate of capsulotomy (long rank test $\mathrm{p}=0.0002$ ). Further analysis showed that cataract severity, and type of anesthesia are not significant variables in predicting PCO and the significance of gender and IOL type was only borderline. Age was also excluded as a possible confounder since the ACP treated group and the non-ACP treated group approximate median ages of 74 and 73 respectively (Table $1 \&$ Table 2). 


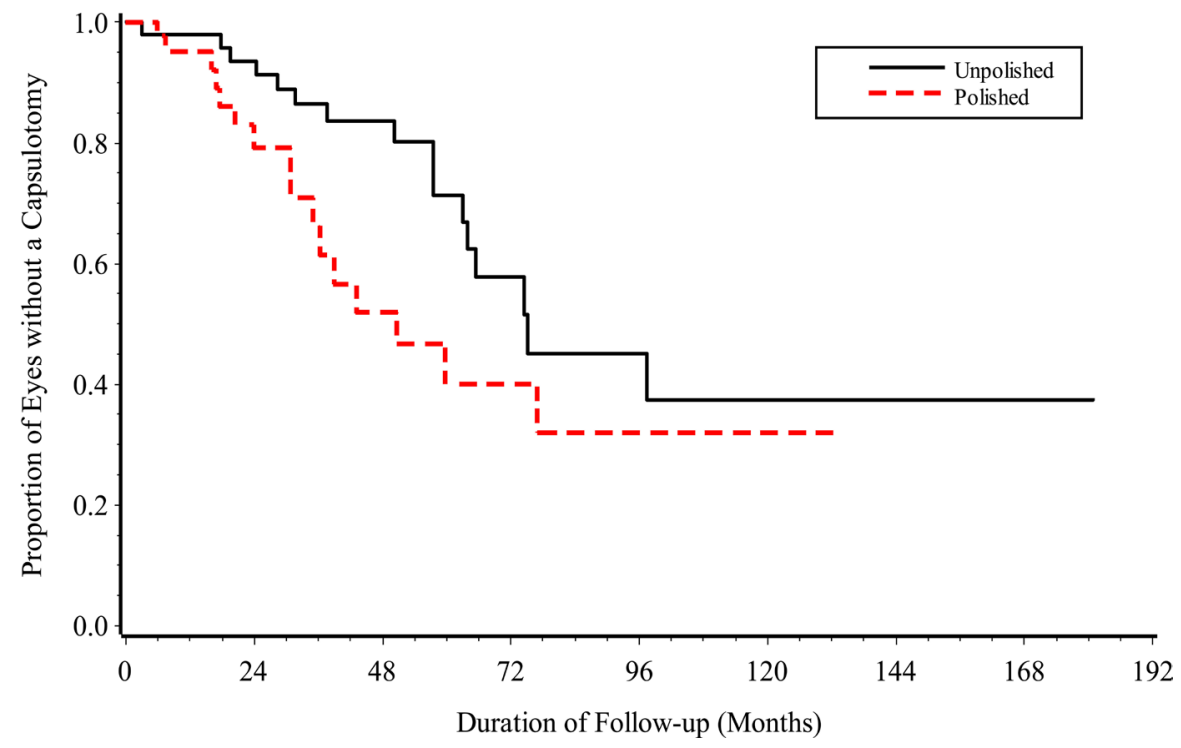

Figure 3. Kaplan Meier survival curve of capsulotomy after cataract surgery by type of procedure (polished vs. unpolished). Only 52 patients who had one eye treated with ACP and the other eye treated without ACP were included in the analysis (total of 104 eyes).

Our findings contradict Nishi's study that showed intraoperative anterior capsule polishing reduces the rate of PCO by 7.1\% [10]. This difference in results could be due to the difference in the technique used to remove the capsular epithelial cells. In our study, a Shepherd-Rentsch capsule polisher was used while Nishi used an ultrasound irrigation/aspiration (I/A) tip to remove the epithelial cells. It has been previously shown that only the ultrasound I/A system gives satisfactory results in removing all of the epithelial cells [7] [18]. Thus, a possible explanation for our results could be that our polishing technique was not successful in removing all of the epithelial cells, However this finding agrees with findings in other studies (Mena-pace et al.) found that anterior capsule polishing with round-edged optic silicone IOLs resulted in an increased Nd:YAG laser capsulotomy [11].

It can be seen in the Kaplan-Meier curves that the ACP procedure was successful in slowing down PCO in the first few months after surgery (Figure 1(b) \& Figure 2(b)). This is because initially after the ACP procedure there are fewer epithelial cells. However, PCO occurs at a faster rate in the ACP group as more time goes by. This could go to show that by disturbing the epithelial cells without their complete removal, we are causing them to proliferate and migrate at a faster rate with less contact inhibition. Thus, it is apparent that better techniques of epithelial cell removal are necessary in order to avoid adverse effects.

The necessity for a more complete method of removing or halting the proliferation of epithelial cells has led other researchers to look for chemical means such as Mitomycin [19] [20], immunotoxin [21] [22], heparin eye drops [23], and the inactivation of the integrin molecule with EDTA to halt epithelial cell migration [24] [25]. All these methods have been shown to be promising in reducing PCO. However, our study shows that until a method can be found to 
completely remove or halt the migration of epithelial cells, less extensive measures are not only insufficient but could also show adverse effects in the long term.

\section{Conclusion}

Polishing the anterior capsule with Shepherd-Rentsch capsule polishers may unexpectedly increase the rate of posterior capsule opacification in eyes with round-edge silicone lenses.

\section{References}

[1] Vasavada, A.R., Raj, S.M., Johar, K. and Nanavaty, M.A. (2006) Effect of Hydrodissection Alone and Hydro Dissection Combined with Rotation on Lens Epithelial Cells; Surgical Approach for the Prevention of Posterior Capsule Opacification. Journal of Cataract \& Refractive Surgery, 32, 145-150.

https://doi.org/10.1016/j.jcrs.2005.11.027

[2] Vasavada, A.R., Dholakia, S.A., Raj, S.M. and Singh, R. (2006) Effect of Cortical Cleaving Hydro Dissection on Posterior Capsule Opacification in Age-Related Nuclear Cataract. Journal of Cataract \& Refractive Surgery, 32, 1196-1200. https://doi.org/10.1016/j.jcrs.2006.03.017

[3] Menapace, R. and Di Nardo, S. (2006) Aspiration Curette for Anterior Capsule Polishing: Laboratory and Clinical Evaluation. Journal of Cataract \& Refractive Surgery, 32, 1997-2003. https://doi.org/10.1016/j.jcrs.2006.07.028

[4] Raut, R.M. (2007) Low-Intensity Ultraviolet Irradiation of the Capsule to Remove Lens Epithelial Cells during Cataract Surgery; Effectiveness and Safety. Journal of Cataract \& Refractive Surgery, 33, 1025-1032.

https://doi.org/10.1016/j.jcrs.2007.02.026

[5] Hanson, R.J., Rubinstein, A., Sarangapani, S., Benjamin, L. and Patel, C.K. (2006) Effect of Lens Epithelial Cell Aspiration on Postoperative Capsulorhexis Contraction with the Use of the AcrySof Intraocular Lens; Randomized Clinical Trial. Journal of Cataract \& Refractive Surgery, 32, 1621-1626. https://doi.org/10.1016/j.jcrs.2006.04.035

[6] Nishi, O. (1989) Lens Epithelial Cell Removal by Ultrasound: Access to 12 o'clock. Journal of Cataract \& Refractive Surgery, 15, 704-706. https://doi.org/10.1016/S0886-3350(89)80042-2

[7] Mathey, C.F., Kohnen, T., Ensikat, H.-J. and Koch, H.-R. (1994) Polishing Methods for the Lens Capsule: Histology and Scanning Electron Microscopy. Journal of Cataract \& Refractive Surgery, 20, 64-69. https://doi.org/10.1016/S0886-3350(13)80046-6

[8] Sacu, S., Menapace, R., Wirtitsch, M., Buehl, W., Rainer, G. and Findl, O. (2004) Effect of Anterior Capsule Polishing on Fibrotic Capsule Opacification: Three-Year Results. Journal of Cataract \& Refractive Surgery, 30, 2322-2327. https://doi.org/10.1016/j.jcrs.2004.02.092

[9] Menapace, R. (2008) Posterior Capsulorhexis Combined with Optic Buttonholing: An Alternative to Standard In-the-Bag Implantation of Sharp-Edged Intraocular Lenses? A Critical Analysis of 1000 Consecutive Cases. Graefe's Archive for Clinical and Experimental Ophthalmology, 246, 787-801. https://doi.org/10.1007/s00417-008-0779-6

[10] Nishi, O. and Nishi, K. (1991) Intercapsular Cataract Surgery with Lens Epithelial 
Cell Removal. Part III: Long-Term Follow-Up of Posterior Capsule Opacification. Journal of Cataract \& Refractive Surgery, 17, 218-220. https://doi.org/10.1016/S0886-3350(13)80253-2

[11] Menapace, R., Wirtitsch, M., Findl, O., Buehl, W., Kriechbaum, K. and Sacu, S. (2005) Effect of Anterior Capsule Polishing on Posterior Capsule Opacification and Neodymium: YAG Capsulotomy Rates: Three-Year Randomized Trial. Journal of Cataract \& Refractive Surgery, 31, 2067-2075. https://doi.org/10.1016/j.jcrs.2005.08.051

[12] Sacu, S., Menapace, R., Findl, O., Georgopoulos, M., Buehl, W., Kriechbaum, K. and Rainer, G. (2004) Influence of Optic Edge Design and Anterior Capsule Polishing on Posterior Capsule Fibrosis. Journal of Cataract \& Refractive Surgery, 30, 658-662. https://doi.org/10.1016/j.jcrs.2003.07.005

[13] Bolz, M., Menapace, R., Findl, O., Sacu, S., Buehl, W., Wirtitsch, M., Leydolt, C. and Kriechbaum, K. (2006) Effect of Anterior Capsule Polishing on the Posterior Capsule Opacification-Inhibiting Properties of a Sharp-Edged, 3-Piece, Silicone Intraocular Lens; Three- and 5-Year Results of a Randomized Trial. Journal of Cataract \& Refractive Surgery, 32, 1513-1520. https://doi.org/10.1016/j.jcrs.2006.04.020

[14] Kruger, A.J., Amon, M., Schauersberger, J., Abela-Formanek, C., Schild, G. and Kolodjaschna, J. (2001) Anterior Capsule Opacification and Lens Epithelial Outgrowth on the Intraocular Lens Surface after Curettage. Journal of Cataract \& Refractive Surgery, 27, 1987-1991. https://doi.org/10.1016/S0886-3350(01)00864-1

[15] Mootha, V.V., Tesser, R. and Qualls, C. (2004) Incidence of and Risk Factors for Residual Posterior Capsule Opacification after Cataract Surgery. Journal of Cataract \& Refractive Surgery, 30, 2354-2358. https://doi.org/10.1016/j.jcrs.2004.03.038

[16] Spalton, D.J. (1999) Posterior Capsule Opacification after Cataract Surgery. Eye, 13, 489-492. https://doi.org/10.1038/eye.1999.127

[17] Koeppl, C., Findl, O., Menapace, R., Kirechbaum, K., Wirtitsch, M., Buehl, W., Sa$\mathrm{cu}$, S. and Drexler, W. (2005) Pilocarpine-Induced Shft of an Accommodating Intraocular Lens: AT-45 Crystalens. Journal of Cataract \& Refractive Surgery, 31, 1290-1297. https://doi.org/10.1016/j.jcrs.2005.03.055

[18] Nishi, O. (1987) Removal of Lens Epithelial Cells by Ultrasound in Endocapsular Cataract Surgery. Ophthalmic Surgery, 18, 577-580.

[19] Shin, D.H., Kim, Y.Y., Ren, J., et al. (1998) Decrease of Capsular Opacification with Adjunctive Mitomycin C in Combined Glaucoma and Cataract Surgery. Ophthalmology, 105, 1222-1226. https://doi.org/10.1016/S0161-6420(98)97024-5

[20] Haus, C.M. and Galand, A.L. (1996) Mitomycin against Posterior Capsule Opacification: An Experimental Study in Rabbits. British Journal of Ophthalmology, 80, 1087-1091. https://doi.org/10.1136/bjo.80.12.1087

[21] Clark, D.S., Emery, J.M. and Munsell, M.F. (1998) Inhibition of Posterior Capsule Opacification with Immunotoxin Specific for Lens Epithelial Cells: 24 Month Clinical Results. Journal of Cataract \& Refractive Surgery, 24, 1614-1620. https://doi.org/10.1016/S0886-3350(98)80352-0

[22] Tarsio, J.F., Kelleher, P.J., Tarsio, M., et al. (1997) Inhibition of Cell Proliferation on Lens Capsule by 4197X-ricin a Immunoconjugate. Journal of Cataract \& Refractive Surgery, 23, 260-266. https://doi.org/10.1016/S0886-3350(97)80351-3

[23] Mastropasqua, L., Lobefalo, L. Ciancaglini, M., et al. (1997) Heparin Eye Drops to Prevent Posterior Capsule Opacification. Journal of Cataract \& Refractive Surgery, 23, 440-446. https://doi.org/10.1016/S0886-3350(97)80191-5

[24] Nishi, O., Nishi, K., Saitoh, I. and Sakanishi, K. (1996) Inhibition of Migrating Lens 
Epithelial Cells by Sustained Relase of Ethylenediaminetetraacetic Acid. Journal of Cataract \& Refractive Surgery, 22, 863-868.

https://doi.org/10.1016/S0886-3350(96)80176-3

[25] Nishi, O., Nishi, K., Mano, C., et al. (1997) Inhibition of Migrating Lens Epithelial Cells by Blocking the Adhesion Molecule Integrin: A Preliminary Report. Journal of Cataract \& Refractive Surgery, 23, 860-865.

https://doi.org/10.1016/S0886-3350(97)80244-1 